\title{
Cognitive Reserve and Alzheimer Disease
}

\author{
Yaakov Stern, PhD
}

\begin{abstract}
Epidemiologic evidence suggests that individuals with higher IQ, education, occupational attainment, or participation in leisure activities have a reduced risk of developing Alzheimer disease (AD). The concept of cognitive reserve (CR) posits that individual differences in how tasks are processed provide differential reserve against brain pathology or age-related changes. This may take 2 forms. In neural reserve, preexisting brain networks that are more efficient or have greater capacity may be less susceptible to disruption. In neural compensation, alternate networks may compensate for pathology's disruption of preexisting networks. Imaging studies have begun to identify the neural substrate of CR. Because CR may modulate the clinical expression of AD pathology, it is an important consideration in studies of "preclinical" $\mathrm{AD}$ and treatment studies. There is also the possibility that directly enhancing CR may help forestall the diagnosis of AD.
\end{abstract}

Key Words: imaging, epidemiology, progression

(Alzheimer Dis Assoc Disord 2006;20:112-117)

\section{DEFINITIONS OF RESERVE}

The idea of reserve against brain damage stems from the repeated observation that there does not seem to be a direct relationship between the degree of brain pathology or brain damage and the clinical manifestation of that damage. For example, Katzman et $\mathrm{l}^{1}$ described 10 cases of cognitively normal elderly women who were discovered to have advanced Alzheimer disease (AD) pathology in their brains at death. They speculated that these women did not express the clinical features of $\mathrm{AD}$ because their brains were larger than average, providing them with "brain reserve."

Brain reserve $e^{2}$ is an example of what might be called passive models of reserve, where reserve derives from brain size or neuronal count. The models are passive because reserve is defined in terms of the amount of brain damage that can be sustained before reaching a threshold

Received for publication January 4, 2006; accepted February 25, 2006. From the Cognitive Neuroscience Division of the Taub Institute, New York, NY; and Departments of Neurology and Psychiatry, Columbia University College of Physicians and Surgeons, New York, NY.

Supported by a grant from the National Institutes on Aging (RO1 AG26158).

Reprints: Yaakov Stern, Taub Institute, 630 W 168th Street, New York, NY 10032 (e-mail: ys11@columbia.edu).

Copyright (C) 2006 by Lippincott Williams \& Wilkins for clinical expression. The threshold model, ${ }^{3}$ one of the best articulated passive models, revolves around the construct of "brain reserve capacity" (BRC). Although $\mathrm{BRC}$ is a hypothetical construct, concrete examples of BRC might include brain size or synapse count. The model recognizes that there are individual differences in BRC. It also presupposes that there is a critical threshold of BRC. Once BRC is depleted past this threshold, specific clinical or functional deficits emerge.

In contrast, the cognitive reserve (CR) model suggests that the brain actively attempts to cope with brain damage by using preexisting cognitive processing approaches or by enlisting compensatory approaches. ${ }^{4}$ Individuals with more $\mathrm{CR}$ would be more successful at coping with the same amount of brain damage. Thus, the same amount of brain damage or pathology will have different effects on different people, even if BRC (eg, brain size) is held constant. The concept of CR provides a ready explanation for why many studies have demonstrated that higher levels of intelligence and of educational and occupational attainment are good predictors of which individuals can sustain greater brain damage before demonstrating functional deficit. Rather than positing that these individuals' brains are grossly anatomically different than those with less reserve (eg, they have more synapses), the CR hypothesis posits that they process tasks in a manner that allows them to cope better with the brain damage.

$\mathrm{I}^{5}$ have suggested that the neural implementation of $\mathrm{CR}$ might take 2 forms: neural reserve and neural compensation. Neural reserve refers to brain networks or cognitive paradigms that are less susceptible to disruption, perhaps because they are more efficient or have greater capacity. Using this type of CR is a normal process that is already in place in healthy individuals. Although healthy individuals may invoke these networks when coping with increased task demands, the networks could also help an individual cope with brain pathology. Neural compensation refers to the process by which individuals suffering from brain pathology use brain structures or networks (and thus cognitive strategies) not normally used by individuals with intact brains to compensate for brain damage. These concepts are particularly important when attempting to formulate and interpret functional imaging studies that investigate CR.

Some research findings might be more easily explained using an active $\mathrm{CR}$ reserve model than a passive model of reserve. For example, given no gross difference in brain size, passive models do not have a 
ready explanation for findings described below, which indicate that 1 patient can maintain more AD pathology than another but appear similar clinically. However, the brain reserve and CR concepts are not mutually exclusive, and it is likely that both are involved in providing reserve against brain damage.

\section{MEASURES OF RESERVE}

For advocates of the idea of brain reserve, anatomic measures such as brain volume, head circumference, synaptic count, or dendritic branching are effective measures of reserve. Mounting evidence suggests that many of these measures are malleable over the lifetime, and influenced by life experience. Therefore, brain reserve may represent a summation of many aspects of life experience that are also thought to summate into CR.

Variables descriptive of lifetime experience are the most commonly used proxies for CR. These include measures of socioeconomic status, such as income or occupational attainment. Educational attainment has also been a widely used proxy for reserve, probably because it is relatively easy to ascertain. Degree of literacy might be a better marker for CR than number of years of formal education because it is a more direct measure of educational attainment. ${ }^{6,7}$ Finally, specific measured attributes have been used as indices of reserve, including IQ and measures of various cognitive functions.

Education might also be a marker for innate intelligence, which may in turn be genetically based or a function of exposures. Some studies suggest that an estimate of IQ, or premorbid IQ, might actually be a more powerful measure of reserve in some cases. ${ }^{8,9}$ Still, education, or other life experiences, probably impart reserve over and above that obtained from innate intelligence. Studies have demonstrated separate or synergistic effects for higher educational and occupational attainment and leisure activities, suggesting that each of these life experiences contributes independently to reserve. ${ }^{10-14}$ A prospective study showed that estimated IQ at age 53 was separately influenced by childhood cognition, educational attainment, and adult occupation. ${ }^{15}$ These observations stress that CR is not fixed; at any point in one's lifetime it results from a combination of exposures.

The simplest explanation for how CR forestalls the clinical effects of AD pathology does not posit that experiences associated with more CR directly affect brain reserve or the development of AD pathology. Rather, CR allows some people to better cope with the pathology and remain clinically more intact for longer periods of time. This has been the working assumption underlying the design and interpretation of many of my studies. However, as mentioned above, many of the factors associated with CR may also have direct impact on the brain itself. There is a demonstrated relationship between IQ and brain volume. ${ }^{16}$ Thus, the child development literature suggests that intracranial brain volume and aspects of lifetime exposure are predictive of differential susceptibility to the effects of traumatic brain injury. ${ }^{17}$ Also, it is now clear that stimulating environments and exercise promote neurogenesis in the dentate of animals. ${ }^{18,19}$ In addition, there is evidence to suggest that environmental enrichment might act directly to prevent or slow the accumulation of AD pathology. ${ }^{20}$ Thus, a more complete accounting of $\mathrm{CR}$ would have to integrate these complex interactions between genetics, the environmental influences on brain reserve and pathology, and the ability to actively compensate for the effects of pathology.

\section{EPIDEMIOLOGIC EVIDENCE FOR CR}

A host of studies have examined the relation between CR proxy variables and incident dementia. Parallel studies have often examined the relation between these variables and cognitive decline in normal aging.

Several studies in India, ${ }^{21}$ England, ${ }^{22}$ and the United States ${ }^{23-25}$ reported no association between education and incident dementia. However, lower incidence of dementia in subjects with higher education has been reported by at least 8 cohorts, in France, ${ }^{26}$ Sweden, ${ }^{27}$ Finland, ${ }^{28}$ China, ${ }^{29}$ and the United States. ${ }^{10,13,30,31}$ Similar associations emerged in a pooled analysis of 4 European population-based prospective studies of individuals 65 years and older. ${ }^{32}$

There is also evidence for the role of education in age-related cognitive decline, with several studies of normal aging reporting slower cognitive and functional decline in individuals with higher educational attainment. ${ }^{3-40}$ These studies suggest that the same educationrelated factors that delay the onset of dementia also allow individuals to cope more effectively with brain changes encountered in normal aging. In an ethnically diverse cohort of nondemented elders in New York City, increased literacy was also associated with slower decline in memory, executive function, and language skills.

No or equivocal association between occupation and incident $\mathrm{AD}$ was found in several population-based longitudinal studies. ${ }^{28,41,42}$ In 2 other prospective studies, occupational position did not predict incident dementia, ${ }^{22}$ or its predictive value might have been mediated by educational status. ${ }^{30}$ Nevertheless, several studies have noted a relationship between occupational attainment and incident dementia. ${ }^{13,31,43-46}$ As mentioned above, occupational attainment was often noted to have independent effects or interact with educational attainment.

In a German population survey, only poor quality living accommodations were associated with increased risk of incident dementia, whereas indicators of social isolation such as low frequency of social contacts within and outside the family circle, low standard of social support and living in single person household did not prove to be significant. ${ }^{43}$ A study from France reported that traveling, doing odd jobs, and knitting were associated with lower risk of incident dementia. ${ }^{47,48}$ Community activities and gardening were also protective for incident dementia in China. ${ }^{44} \mathrm{~A}$ longitudinal study in 
Sweden reported that having an extensive social network was protective for development of incident dementia. ${ }^{49}$ The same group later reported that engagement in mental, social, and productive activities was associated with decreased risk for incident dementia. ${ }^{50}$ Participation in a variety of leisure activities characterized as intellectual (eg, reading, playing games, going to classes) or social (eg, visiting friends or relatives etc.) was assessed in another population study of nondemented elderly in New York. ${ }^{51}$ During follow-up, subjects with high leisure activity had $38 \%$ less risk of developing dementia. In another prospective study, frequency of participation in common cognitive activities (ie, reading a newspaper, magazine, books) was assessed at baseline for 801 elderly Catholic nuns, priests, and brothers without dementia. ${ }^{52}$ During follow-up, 1-point increase in the cognitive activity score was associated with a $33 \%$ reduction in the risk for AD. Additionally, engagement in cognitive activities was also associated with slower rates of cognitive decline. Finally, in another prospective cohort from New York, participation in leisure activities, particularly reading, playing board games or musical instruments, and dancing, was associated with a reduced risk for incident dementia. ${ }^{53}$ Increased participation in cognitive activities was also associated with reduced rates of memory decline in this study.

In contrast to the studies above, in which greater reserve was associated with better outcomes, a series of studies of patients with AD have suggested that those with higher reserve have poorer outcomes. In a prospective study of AD patients matched for clinical severity at baseline, ${ }^{54}$ patients with greater education or occupational attainment died sooner than those with less attainment. Although at first these findings seem contra-intuitive, they are consistent with the CR hypothesis. The hypothesis predicts that at any level of assessed clinical severity, the underlying pathology of $\mathrm{AD}$ is more advanced in patients with CR than in those with CR. This would result in the clinical disease emerging when pathology is more advanced, as suggested by the incidence studies reviewed above. This disparity in degree of pathology would be present at more advanced clinical stages of the disease as well. At some point the greater degree of pathology in the high reserve patients would result in more rapid death. Although one study did not replicate this finding, ${ }^{55}$ a follow-up study by the same group, using patients with more advanced dementia, did. ${ }^{56}$ Higher measured CR has also been associated with more rapid cognitive decline in patients with AD. ${ }^{57,58}$ Explanation of this finding is along similar lines. At some point, AD pathology must become too severe enough to support the processes that mediate CR. This point should arrive at an earlier stage of clinical severity in patients with higher CR because the underlying $\mathrm{AD}$ pathology is more severe.

\section{IMAGING STUDIES OF CR}

Several imaging studies of $\mathrm{CR}$ in $\mathrm{AD}$ used resting cerebral blood flow (CBF) as a surrogate for $\mathrm{AD}$ pathology. ${ }^{59-61}$ In patients matched for clinical severity, these studies have found negative correlations between resting $\mathrm{CBF}$ and years of education, premorbid IQ, occupation and leisure. ${ }^{9,14,62,63}$ The negative correlations are consistent with the CR hypothesis' prediction that at any given level of disease clinical severity a subject with a higher level of $\mathrm{CR}$ should have greater AD pathology (ie, lower $\mathrm{CBF}$ ). These findings were confirmed in a prospective study with subsequent neuropathologic analysis. Education was found to modify the association between AD pathology and levels of cognitive function: for the same degree of brain pathology there was better cognitive function with each year of education. ${ }^{64}$

In contrast to the resting studies, cognitive activation studies can be used to elucidate the nature of CR. The general logic behind this approach is that to the extent that CR reflects differences in how tasks are processed, functional imaging studies should be able to capture these differences. One approach to this problem is to identify patterns of task-related activation that differ between AD patients and controls, and to determine whether they are compensatory. For example, Stern et $\mathrm{al}^{65}$ tried to determine whether or not the pathology of AD alters the brain networks subserving performance on a memory task, while carefully controlling for task difficulty. $\mathrm{H}_{2}^{15} \mathrm{O}$ positron emission tomography was used to measure regional $\mathrm{CBF}$ in patients and healthy elders during the performance of a verbal recognition task. Task difficulty was matched across participants by adjusting the size of the list that each subject had to remember such that each subject's recognition accuracy was $75 \%$. In the healthy elders, a network of brain areas involving left anterior cingulate, anterior insula, and left basal ganglia was activated during task performance. Higher study list size was associated with increased recruitment of this network, indicating that this network was associated with task performance and that subjects who could recruit the network to a greater degree could perform the task better. Only 3 AD patients expressed this network in a similar manner. This network used by the controls and a minority of AD patients may underlie neural reserve, in that it seems to be recruited to cope with the demands presented by the activation task, and differential recruitment of the network is directly related to the ability to perform the task. Individuals who are able to activate this network to a greater degree may have more reserve against brain damage. The remaining $11 \mathrm{AD}$ patients recruited a different network during task performance, consisting of left posterior temporal cortex, calcarine cortex, posterior cingulate, and the vermis. Again, in these patients, higher study list size was associated with increased activation of this network. Stern et al hypothesized that this alternate network may be used by the AD patients to compensate for the effects of AD pathology. This is compatible with the concept of neural compensation, where patients use brain networks not used by unaffected individuals to perform a task.

Whereas the criteria for neural compensation merely require that individuals with pathology use a 
brain network that is not used by unaffected individuals, one may further ask whether use of this alternate network is associated with better performance. For example, in several studies, some elders showed additional activation in areas contralateral to those activated by younger subjects; the elders who showed this additional activation performed better than those who did not, indicating that it was compensatory. ${ }^{66,67}$ Similarly, studies have shown that additional activation in $\mathrm{AD}$ patients compared with controls is compensatory. ${ }^{68}$

Other studies have taken a more direct approach to investigating brain networks associated with CR. One positron emission tomography study identified brain areas whose activation during performance of a nonverbal memory task correlated with an index of CR calculated from measures of education and literacy. ${ }^{69}$ Such areas were identified in both healthy controls and patients with $\mathrm{AD}$, suggesting that these areas may reflect the neural instantiation of CR. Interestingly, in some brain areas the directionality of the association between $\mathrm{CR}$ and cerebral activation differed in healthy controls and AD patients. For example, some brain areas showed increased activation as a function of increased CR in the elderly controls and decreased activation in the AD patients. Given the assumption that individuals with higher measured CR would activate in a more adaptive way, these findings suggest that there has been some compensation for the effects of AD pathology in the AD patients and that $\mathrm{CR}$ is mediated differently in the patients and controls. The changes in activation in the AD patients are consistent with our definition of neural compensation. Similar observations have been noted in comparisons of young and elderly subjects. ${ }^{5}$

In summary, the imaging evidence is beginning to provide support for the 2 hypothesized neural mechanisms underlying CR: neural reserve which emphasizes preexisting differences in neural efficiency or capacity, and neural compensation, which reflects individual differences in the ability to develop new, compensatory responses to the disabling effects of pathology.

\section{IMPLICATIONS OF CR FOR DIAGNOSIS, EARLY DETECTION, AND TREATMENT OF AD}

The evidence suggests that 2 individuals who appear the same clinically can have widely divergent levels of underlying $\mathrm{AD}$ pathology and that $\mathrm{CR}$ may account for some of this disparity. This observation has strong implications for our attempt to diagnose $\mathrm{AD}$ in its preclinical stages. For example, setting aside diagnostic errors, the clinical observation of mild cognitive impairment may be accompanied by very minimal pathology or more than enough to meet pathologic criteria for AD. A proportion of this variability may be explained by CR. Measuring CR therefore becomes an important component of the diagnostic process.

Most people recognize that clinical evaluation alone is an insufficient measure of a patient's true status, and there are active attempts to seek markers of underlying
AD pathology. It remains to be seen whether the best index of pathology will be via biomarkers, ${ }^{70}$ or by imaging $\mathrm{AD}$ pathology itself, ${ }^{71}$ the effect of pathology on resting metabolism in entire brain, ${ }^{72}$ or the effect of pathology on particularly vulnerable brain area. ${ }^{73}$ However, even with the addition of an accurate index of $\mathrm{AD}$ pathology, clinical characterization is not complete. Also needed is a measure of an individual's CR, that is, the ability to cope with this pathology. Some idea of an individual's CR might be garnered from standard proxies for CR such as educational and occupational attainment. However, as functional imaging studies reveal greater insight into the neural networks that underlie CR, quantifying a patient's expression of such networks might allow us to directly assess CR in individual patients. The combination of clinical characterization, measures of underlying pathology and indices of CR would provide a more complete picture of a patient's status. Besides being important for early diagnosis, such an approach would help determine prognoses and progression over time. It would also be crucial for the assessment of the effect of any intervention, particularly one that purports to influence time of disease onset.

Finally, the fact that different life exposures including education, occupation and leisure, impart reserve against $\mathrm{AD}$ in epidemiologic studies raises the possibility that an individual's CR could be increased through some set of systematic exposures or interventions. This would result in a nonpharmacologic approach for reducing risk of developing AD.

\section{REFERENCES}

1. Katzman R, Aronson M, Fuld P, et al. Development of dementing illnesses in an 80-year-old volunteer cohort. Ann Neurol. 1989;25: 317-324.

2. Katzman R. Education and the prevalence of dementia and Alzheimer's disease. Neurology. 1993;43:13-20.

3. Satz P. Brain reserve capacity on symptom onset after brain injury: a formulation and review of evidence for threshold theory. Neuropsychology. 1993; 7:273-295.

4. Stern Y. What is cognitive reserve? Theory and research application of the reserve concept. J Int Neuropsychol Soc. 2002;8:448-460.

5. Stern Y, Habeck C, Moeller J, et al. Brain networks associated with cognitive reserve in healthy young and old adults. Cereb Cortex. 2005; 15:394-402.

6. Manly JJ, Touradji P, Tang M-X, et al. Literacy and memory decline among ethnically diverse elders. J Clin Exp Neuropsychol. 2003;5:680-690.

7. Manly JJ, Schupf N, Tang MX, et al. Cognitive decline and literacy among ethnically diverse elders. $J$ Geriatr Psychiatry Neurol 2005; 18:213-217

8. Albert SM, Teresi JA. Reading ability, education, and cognitive status assessment among older adults in Harlem, New York City. AJPH. 1999;89:95-97.

9. Alexander GE, Furey ML, Grady CL, et al. Association of premorbid function with cerebral metabolism in Alzheimer's disease: implications for the reserve hypothesis. Am J Psychiatr. 1997;154: 165-172.

10. Evans DA, Beckett LA, Albert MS, et al. Level of education and change in cognitive function in a community population of older persons. Ann Epidemiol. 1993;3:71-77.

11. Mortel KF, Meyer JS, Herod B, et al. Education and occupation as risk factors for dementia of the Alzheimer and ischemic vascular types. Dementia. 1995;6:55-62. 
12. Rocca WA, Bonaiuto S, Lippi A, et al. Prevalence of clinically diagnosed Alzheimer's disease and other dementing disorders: a door-to-door survey in Appignano, Macerata Province, Italy. Neurology. 1990;40:626-631.

13. Stern Y, Gurland B, Tatemichi TK, et al. Influence of education and occupation on the incidence of Alzheimer's disease. $J$ Am Med Assoc. 1994;271:1004-1010.

14. Stern Y, Alexander GE, Prohovnik I, et al. Relationship between lifetime occupation and parietal flow: implications for a reserve against Alzheimer's disease pathology. Neurology. 1995;45:55-60.

15. Richards M, Sacker A. Lifetime antecedents of cognitive reserve. J Clin Exp Neuropsychol. 2003;25:614-624.

16. Willerman L, Schultz R, Rutledge JN, et al. In vivo brain size and intelligence. Intelligence. 1991;15:223-228.

17. Kesler SR, Adams HF, Blasey CM, et al. Premorbid intellectual functioning, education, and brain size in traumatic brain injury: an investigation of the cognitive reserve hypothesis. Appl Neuropsychol. 2003; 10:153-162.

18. Brown J, Cooper-Kuhn CM, Kemperman G, et al. Enriched environment and physical activity stimulate hippocampal but not olfactory bulb neurogenesis. Eur J Neurosci. 2003;17:2042-2046.

19. van Praag H, Shubert T, Zhao C, et al. Exercise enhances learning and hippocampal neurogenesis in aged mice. J Neurosci. 2005;25: $8680-8685$.

20. Lazarov O, Robinson J, Tang YP, et al. Environmental enrichment reduces Abeta levels and amyloid deposition in transgenic mice. Cell. 2005;120:701-713.

21. Chandra V, Pandav R, Dodge HH, et al. Incidence of Alzheimer's disease in a rural community in India: the Indo-US study. Neurology. 2001;57:985-989.

22. Paykel ES, Brayne C, Huppert FA, et al. Incidence of dementia in a population older than 75 years in the United Kingdom. Arch Gen Psy. 1994;54:325-332.

23. Hall KS, Gao S, Unverzagt FW, et al. Low education and childhood rural residence: risk for Alzheimer's disease in African Americans. Neurology. 2000;54:95-99.

24. Cobb JL, Wolf PA, Au R, et al. The effect of education on the incidence of dementia and Alzheimer's disease in the Framingham study. Neurology. 1995;45:1707-1712.

25. Graves AB, Larson EB, Edland SD, et al. Prevalence of dementia and its subtypes in the Japanese American population of King County, Washington state. The Kame project. Am J Epi. 1996; 144:760-771.

26. Letenneur L, Commenges D, Dartigues JF, et al. Incidence of dementia and Alzheimer's disease in elderly community residents of south-western France. Int J Epidemiol. 1994;23:1256-1261.

27. Qiu C, Backman L, Winblad B, et al. The influence of education on clinically diagnosed dementia incidence and mortality data from the Kungsholmen Project. Arch Neurol. 2001;58:2034-2039.

28. Anttila T, Helkala EL, Kivipelto $M$, et al. Midlife income, occupation, APOE status, and dementia: a population-based study. Neurology. 2002;59:887-893.

29. Zhang M, Katzman R, Salmon D, et al. The prevalence of dementia and Alzheimer's disease in Shanghai, China: impact of age, gender and education. Ann Neurol. 1990;27:428-437.

30. Evans DA, Hebert LE, Beckett LA, et al. Education and other measures of socioeconomic status and risk of incident Alzheimer disease in a defined population of older persons. Arch Neurol. 1997;54:1399-1405.

31. White L, Katzman R, Losonczy K, et al. Association of education with incidence of cognitive impairment in three established populations for epidemiologic studies of the elderly. $J$ Clin Epidemiol. 1994;47:363-374.

32. Launer LJ, Andersen K, Dewey ME, et al. Rates and risk factors for dementia and Alzheimer's disease: results from EURODEM pooled analyses. EURODEM incidence research group and work groups. European studies of dementia. Neurology. 1999;52: $78-84$.

33. Albert MS, Jones K, Savage CR, et al. Predictors of cognitive change in older persons: MacArthur studies of successful aging. Psych Aging. 1995; 10:578-589.
34. Butler SM, Ashford JW, Snowdon DA. Age, education, and changes in the mini-mental state exam scores of older women: findings from the Nun study. JAGS. 1996;44:675-681.

35. Chodosh J, Reuben DB, Albert MS, et al. Predicting cognitive impairment in high-functioning community-dwelling older persons: MacArthur studies of successful aging. $J$ Am Geriatr Soc. 2002;50:1051-1060.

36. Christensen H, Korten AE, Jorm AF, et al. Education and decline in cognitive performance: compensatory but not protective. Int $J$ Geriatr Psychiatry. 1997;12:323-330.

37. Farmer ME, Kittner SJ, Rae DS, et al. Education and change in cognitive function: the epidemiologic catchment area study. Ann Epidemiol. 1995;5:1-7.

38. Snowdon DA, Ostwald SK, Kane RL. Education, survival and independence in elderly Catholic sisters, 1936-1988. Am J Epidemiol. 1989;130:999-1012.

39. Lyketsos CG, Chen L-S, Anthony JC. Cognitive decline in adulthood: an 11.5-year follow-up of the baltimore epidemiologic catchment area study. Am J Psychiatry. 1999;156:58-65.

40. Colsher PL, Wallace RB. Longitudinal application of cognitive function measures in a defined population of community-dwelling elders. Ann Epidemiol. 1991;1:215-230.

41. Helmer C, Letenneur L, Rouch I, et al. Occupation during life and risk of dementia in French elderly community residents. $J$ Neurol Neurosurg Psychiatry. 2001;71:303-309.

42. Jorm AF, Rodgers B, Henderson AS, et al. Occupation type as a predictor of cognitive decline and dementia in old age. Age Ageing. 1998;27:477-483.

43. Bickel H, Cooper B. Incidence and relative risk of dementia in an urban elderly population: findings of a prospective field study. Psychol Med. 1994;24:179-192.

44. Zhang X, Li C, Zhang M. Psychosocial risk factors of Alzheimer's disease. Zhonghua Yi Xue Za Zhi. 1999;79:335-338.

45. Qiu C, Karp A, von Strauss E, et al. Lifetime principal occupation and risk of Alzheimer's disease in the Kungsholmen project. Am J Ind Med. 2003;43:204-211.

46. Schmand B, Smit JH, Geerlings MI, et al. The effects of intelligence and education on the development of dementia. A test of the brain reserve hypothesis. Psychol Med. 1997;27:1337-1344.

47. Fabrigoule C, Letenneur L, Dartigues JF, et al. Social and leisure activities and risk of dementia: a prospective longitudinal study. J Am Geriatr Soc. 1995;43:485-490.

48. Helmer C, Damon D, Letenneur L, et al. Marital status and risk of Alzheimer's disease: a French population-based cohort study. Neurology. 1999;53:1953-1958.

49. Fratiglioni L, Wang HX, Ericsson K, et al. Influence of social network on occurrence of dementia: a community-based longitudinal study. Lancet. 2000;355:1315-1319.

50. Wang H-X, Karp A, Winblad B, et al. Late-life engagement in social and leisure activities is associated with a decreased risk of dementia: a longitudinal study from the Kungsholmen project. $\mathrm{Am} J$ Epidemiol. 2002;155:1081-1087.

51. Scarmeas N, Levy G, Tang MX, et al. Influence of leisure activity on the incidence of Alzheimer's disease. Neurology. 2001;57:2236-2242.

52. Wilson RS, Mendes De Leon CF, Barnes LL, et al. Participation in cognitively stimulating activities and risk of incident Alzheimer disease. J Am Med Assoc. 2002;287:742-748.

53. Verghese J, Lipton RB, Katz MJ, et al. Leisure activities and the risk of dementia in the elderly. $N$ Engl J Med. 2003;348:2508-2516.

54. Stern Y, Tang MX, Denaro J, et al. Increased risk of mortality in Alzheimer's disease patients with more advanced educational and occupational attainment. Ann Neurol. 1995;37:590-595.

55. Geerlings MI, Deeg DJH, Schmand B, et al. Increased risk of mortality in Alzheimer's disease patients with higher education? A replication study. Neurology. 1997;49:798-802.

56. Geerlings MI, Deeg DJH, Penninx BW, et al. Cognitive reserve and mortality in dementia: the role of cognition, functional ability and depression. Psychol Med. 1999;29:1219-1226.

57. Stern Y, Albert S, Tang MX, et al. Rate of memory decline in AD is related to education and occupation: cognitive reserve? Neurology. 1999;53:1942-1957. 
58. Scarmeas N, Albert SM, Manly JJ, et al. Education and rates of cognitive decline in incident Alzheimer's disease. JNNP. 2006;77: 308-316.

59. DeCarli C, Atack JR, Ball MJ, et al. Post-mortem regional neurofibrillary tangle densities but not senile plaque densities are related to regional cerebral metabolic rates for glucose during life in Alzheimer's disease patients. Neurodegen. 1992;1:113-121.

60. Friedland RP, Brun A, Bundinger TF. Pathological and positron emission tomographic correlations in Alzheimer's disease. Lancet. $1985 ; 1-28$

61. McGeer EG, McGeer PL, Harrop R, et al. Correlations of regional postmortem enzyme activities with premortem local glucose metabolic rates in Alzheimer's disease. J Neurosci Res. 1990;27: 612-619.

62. Stern Y, Alexander GE, Prohovnik I, et al. Inverse relationship between education and parietotemporal perfusion deficit in Alzheimer's disease. Ann Neurol. 1992;32:371-375.

63. Scarmeas N, Zarahn E, Anderson KE, et al. Association of life activities with cerebral blood flow in Alzheimer disease-implications for the cognitive reserve hypothesis. Arch Neurol. 2003;60: 359-365.

64. Bennett DA, Wilson RS, Schneider JA, et al. Education modifies the relation of $\mathrm{AD}$ pathology to level of cognitive function in older persons. Neurology. 2003;60:1909-1915.

65. Stern Y, Moeller JR, Anderson KE, et al. Different brain networks mediate task performance in normal aging and $\mathrm{AD}$ : defining compensation. Neurology. 2000;55:1291-1297.
66. Cabeza R, Anderson ND, Locantore JK, et al. Aging gracefully: compensatory brain activity in high-performing older adults. Neuroimage. 2002;17:1394-1402.

67. Rosen AC, Prull MW, O'Hara R, et al. Variable effects of aging on frontal lobe contributions to memory. Neuroreport. 2002;13: 2425-2428.

68. Grady CL, McIntosh AR, Beig S, et al. Evidence from functional neuroimaging of a compensatory prefrontal network in Alzheimer's disease. J Neurosci. 2003;23:986-993.

69. Scarmeas N, Zarahn E, Anderson KE, et al. Cognitive reservemediated modulation of positron emission tomographic activations during memory tasks in Alzheimer disease. Arch Neurol. 2004;61: 73-78.

70. Frank RA, Galasko D, Hampel H, et al. Biological markers for therapeutic trials in Alzheimer's disease. Proceedings of the biological markers working group; NIA initiative on neuroimaging in Alzheimer's disease. Neurobiol Aging. 2003;24:521-536.

71. Wengenack TM, Curran GL, Poduslo JF. Targeting Alzheimer amyloid plaques in vivo. Nat Biotechnol. 2000;18:868-872.

72. Scarmeas N, Habeck CG, Zarahn E, et al. Covariance PET patterns in early Alzheimer's disease and subjects with cognitive impairment but no dementia: utility in group discrimination and correlations with functional performance. Neuroimage. 2004;23:35-45.

73. Small SA, Perera GM, Delapaz R, et al. Differential regional dysfunction of the hippocampal formation among elderly with memory decline and Alzheimer's disease. Ann Neurol. 1999; 45:466-472. 